\title{
Forearm Bone Mineral Density of Normal Indian Population
}

\author{
Ravichandran Rajan ${ }^{1,2}$, Kannan Subramanian² \\ ${ }^{1}$ MIOT Hospital, Chennai, India \\ ${ }^{2}$ Madras Institute of Nephrology Research Private Ltd., Chennai, India \\ Email: mionresearch@yahoo.com \\ Received $* * * * 2014$ \\ Copyright (C) 2014 by authors and OALib. \\ This work is licensed under the Creative Commons Attribution International License (CC BY). \\ http://creativecommons.org/licenses/by/4.0/

(c) $\underset{E Y}{0}$ Open Access

\section{Abstract}

Background and Objectives: Bone density measurements by dual-energy X-ray absorptiometry (DEXA) recognized now as a safe and accurate technique [1] is being done frequently. But the Tscore and Z-score values are interpreted using the reference value of Asian population provided by the manufacturer and not of Indian population. This may lead to improper diagnosis of Osteoporosis in Indian population. In this context we compared the young reference values and age-related values of bone density of the normal Indian population with the reference value of Asian population provided by the manufacturer. Methods: Through DEXA normal healthy individuals who were prospective renal donors were scanned. Results \& Conclusion: Bone Mineral Density (BMD) of distal radius and ulna, proximal radius and ulna, proximal radius of normal Indian female and BMD of proximal radius and ulna of male population are found to be less considering the reference value of Asian population provided by the manufacturer. Hence it may be inappropriate to use the reference value of Asian population provided by the manufacturer to calculate the $T$ score and Z-score in Indian population.

\section{Keywords}

Bone Mineral Density, DEXA, Indian Population

Subject Areas: Diabetes \& Endocrinology, Epidemiology, Orthopedics, Radiology \& Medical Imaging

\section{Introduction}

The prevention, diagnosis and management of loss of bone density due to any cause depend upon bone density measurements. DEXA is currently considered as the method of choice. With this method, the patient at risk for Osteoporosis can be identified so that appropriate clinical interventions to prevent fracture can be undertaken. DEXA also allows assessment of the efficacy of these interventions in preventing bone loss [2]. 
Osteoporosis, which is an important cause for morbidity in old age [3] [4] is usually defined with reference to a pre-set standard value provided by the manufacturing company. BMD is usually expressed in terms of T-score and Z-score. It is because that the BMD has to be compared with healthy population expressed in terms of standard deviation relative to that population to interpret the value. T-score is a standard deviation from the healthy young population and Z-score is an age-related standard deviation from healthy population of that particular age. According to World Health Organization, Osteopenia is defined as T-score between -1 and -2.4 , and Osteoporosis as T-score $<-2.5[5]$.

The purpose of this study is to compare the young reference values and age-related values of bone density of the Indian population with the reference value of Asian population provided by the manufacturer.

\section{Material and Methods}

Sample size was calculated using population survey or descriptive study using random (not cluster) sampling. A total of 319 patients over a period of 5 years were studied which included 115 females of mean age $36(S D \pm 12)$ and 204 males of mean age 30 (SD \pm 10 ) (Table 1).

The bone mineral density was measured using dual energy X-ray absorptiometry, multiple detector, rectilinear scan (model pDEXA forearm X-ray bone densitometer, Norland medical systems, Inc., W6340 Hackbarth road, Fort Atkinson, WI 53538). The areas scanned were proximal radius and ulna, distal radius and ulna, proximal radius.

These 319 patients included normal healthy individuals who were prospective renal donors. Excluded were persons having chronic illness like diabetes, chronic liver diseases, chronic heart diseases, chronic lung diseases, those on steroids [6], those having bone disorders [7], stroke patients [8] and those with a history of fracture forearm. Postmenopausal women were confirmed not to be suffering from bone problems. Pregnant [9] and lactating females [10] were also excluded. Donors were included only after they passed the routine medical tests.

Young reference value was calculated as the average of BMD at the age of 20. Averages of BMD of persons age falling in each decade was calculated and used as reference value for end of each decade. A line chart was constructed using age (interval of 10) in X-axis and BMD in Y-axis. Appropriate age related BMD was arrived at by point of intercepts. This age related BMD was used to compare with age related BMD recommended for Asian population by the manufacturing company. T-test for paired samples was used for comparison.

\section{Results}

The bone mineral density ( \pm one standard deviation) at the age of 20 for Indian female population of distal radius and ulna is $0.314( \pm 0.04)$, that of proximal radius and ulna is $0.692( \pm 0.06)$ and that of proximal radius is 0.719 $( \pm 0.05)$. In case of male population BMD of distal radius and ulna is $0.379( \pm 0.06)$, that of proximal radius and ulna is $0.809( \pm 0.09)$, and that of proximal radius is $0.817( \pm 0.09)$.

From here the BMD is found to increase till 40 years of age and after the age of 40 BMD shows a steady decline (Table 2 and Table 3).

\begin{tabular}{ccc} 
Table 1. Age distribution. & & \\
\hline Age & Female & Male \\
\hline$<20$ & 11 & 22 \\
$21-30$ & 33 & 102 \\
$31-40$ & 28 & 53 \\
$41-50$ & 29 & 17 \\
$51-60$ & 11 & 8 \\
$61-70$ & 3 & 2 \\
Total & 115 & 204 \\
\hline
\end{tabular}


Table 2. Female BMD of normal population.

\begin{tabular}{cccc}
\hline Age & BMD Distal Radius and Ulna (SD) & BMD Proximal Radius and Ulna (SD) & BMD Proximal Radius (SD) \\
\hline 20 & $0.314( \pm 0.04)$ & $0.692( \pm 0.06)$ & $0.719( \pm 0.05)$ \\
30 & $0.317( \pm 0.05)$ & $0.735( \pm 0.07)$ & $0.753( \pm 0.08)$ \\
40 & $0.327( \pm 0.06)$ & $0.736( \pm 0.07)$ & $0.752( \pm 0.07)$ \\
50 & $0.292( \pm 0.05)$ & $0.691( \pm 0.08)$ & $0.702( \pm 0.08)$ \\
60 & $0.271( \pm 0.03)$ & $0.616( \pm 0.06)$ & $0.633( \pm 0.07)$ \\
70 & $0.252( \pm 0.02)$ & $0.581( \pm 0.17)$ & $0.598( \pm 0.17)$ \\
\hline
\end{tabular}

Table 3. Male BMD of normal population.

\begin{tabular}{cccc}
\hline Age & BMD Distal Radius and Ulna (SD) & BMD Proximal Radius and Ulna (SD) & BMD Proximal Radius (SD) \\
\hline 20 & $0.379( \pm 0.06)$ & $0.809( \pm 0.09)$ & $0.817( \pm 0.09)$ \\
30 & $0.401( \pm 0.05)$ & $0.857( \pm 0.08)$ & $0.863( \pm 0.08)$ \\
40 & $0.387( \pm 0.05)$ & $0.882( \pm 0.07)$ & $0.885( \pm 0.08)$ \\
50 & $0.379( \pm 0.05)$ & $0.843( \pm 0.07)$ & $0.851( \pm 0.07)$ \\
60 & $0.377( \pm 0.09)$ & $0.837( \pm 0.08)$ & $0.846( \pm 0.08)$ \\
70 & $0.369( \pm 0.03)$ & $0.831( \pm 0.123)$ & $0.841( \pm 0.144)$ \\
\hline
\end{tabular}

The young reference value of our female population was compared with Asian female population reference provided by manufacturer and was found to be lower $(P=0.037)$. Similarly young reference value of our male population was compared with Asian male population reference. It is found to be lower $(P=0.039)$ (Table 4).

The age related BMD in our study of the normal population was compared with the Asian reference value provided by manufacture. Our population has a significant lower age related BMD than the Asian reference value provided by manufacturer (Table 5 and Table 6). Testing for significance between these two groups revealed that except for male distal radius and ulna, proximal radius, others were statistically significant $(p<$ $0.05)$.

\section{Discussion}

Various methods are available for measuring bone density like DEXA, Dual-photon absorptiometry (DPA) [11] [12], Quantitative ultrasound (QUS) [13] and Computed tomography (CT) [14] [15]. DEXA is currently considered the bone densitometric technique of choice [1] [2]. DEXA is found to have a low radiation exposure (less than 0.1 microGy) [16]. The common sites scanned for BMD are spine, hip and forearm. Ryan, P.J., Blake, G.M., Herd, R., Parker, J., and Fogelman, I., has concluded that for the discrimination of normal and Osteoporotic women the three forearm sites are comparable [17].

Study by Nagia, S., Arya, V., Verma, B.R., Gujral, R.B., and Mithal, A., from Lucknow (1997) has suggested that the mean spinal BMD in normal healthy Indian females is significantly lower as compared to AmericanEuropean population [18]. Even Patlay et al. in England has found statistically significant difference between the local young normal reference BMD data and the densitometer manufacturer's normal data in south England women [19]. Anburajan M., et al. studied the BMD of femur in south Indian women. It revealed that the peak BMD values of south Indian female population were also less compared to American white women. The peak bone mass seems to occur one decade later in south Indian women than the Americans, while the loss of density seems to occur early and faster in Americans compared to south Indian women [20].

In our study we have found that BMD of our normal population at different age is significantly lower when compared with the reference value of Asian population provided by the manufacturer except for density of distal radius and ulna, proximal radius of the Indian male. 
Table 4. Comparison of young reference value between Indian and Asian population.

\begin{tabular}{ccccc}
\hline & \multicolumn{2}{c}{ Female } & \multicolumn{2}{c}{ Male } \\
\hline Region & Asian $( \pm 2$ SD) & Indian $( \pm 2$ SD $)$ & Asian $( \pm 2$ SD) & Indian $( \pm 2$ SD $)$ \\
\hline Distal Radius and Ulna & $0.346( \pm 0.0962)$ & $0.314( \pm 0.08)$ & $0.423( \pm 0.1322)$ & $0.379( \pm 0.12)$ \\
Proximal Radius and Ulna & $0.793( \pm 0.1352)$ & $0.692( \pm 0.12)$ & $0.943( \pm 0.1768)$ & $0.809( \pm 0.18)$ \\
Proximal Radius & $0.792( \pm 0.1258)$ & $0.719( \pm 0.1)$ & $0.959( \pm 0.1724)$ & $0.817( \pm 0.18)$ \\
\hline
\end{tabular}

Table 5. Comparison of age wise BMD between Asian and Indian females.

\begin{tabular}{cllllll}
\hline & \multicolumn{2}{c}{ Distal Radius \& Ulna } & \multicolumn{2}{c}{ Proximal Radius \& Ulna } & \multicolumn{2}{c}{ Proximal Radius } \\
\hline Age & Asian & Indian & Asian & Indian & Asian & Indian \\
\hline 20 & 0.346 & 0.314 & 0.792 & 0.692 & 0.793 & 0.719 \\
40 & 0.344 & 0.327 & 0.796 & 0.736 & 0.782 & 0.752 \\
45 & 0.344 & 0.310 & 0.797 & 0.714 & 0.779 & 0.727 \\
65 & 0.251 & 0.262 & 0.634 & 0.599 & 0.618 & 0.616 \\
86 & 0.251 & 0.220 & 0.589 & 0.486 & 0.562 & 0.509 \\
\hline
\end{tabular}

Table 6. Comparison of age wise BMD between Asian and Indian males.

\begin{tabular}{clcccccc}
\hline & \multicolumn{2}{c}{ Distal Radius \& Ulna } & \multicolumn{2}{c}{ Proximal Radius \& Ulna } & \multicolumn{2}{c}{ Proximal Radius } \\
\hline Age & Asian & Indian & Asian & Indian & Asian & Indian \\
\hline 20 & 0.423 & 0.379 & 0.959 & 0.809 & 0.943 & 0.817 \\
35 & 0.439 & 0.394 & 0.94 & 0.869 & 0.922 & 0.874 \\
85 & 0.361 & 0.357 & 0.877 & 0.822 & 0.852 & 0.834 \\
\hline
\end{tabular}

As either T-score or Z-score value of a patient depends on the BMD of normal population, both of them are bound to differ when compared with Indian normal population reference and with the reference value of Asian population provided by the manufacturer. Decision on treatment modalities for decreased bone mineralization in turn depends upon the degree of loss in density in terms of T-score and Z-score along with consideration of age, sex, and underlying etiological factors. If the young reference value and the age-related values as found in our study are to be used instead of the values given by the manufacturer, then the diagnosis of Osteoporosis and Osteopenia are going to be different. It is necessary in future to replicate the study in a larger healthy population.

\section{References}

[1] Fordham, J.N., Simpson, Pitcher, O., Bates, J. and Jones, S.B. (1994) An Open Access Bone Densitometry Service: Report of First Year's Operation. The British Journal of Rheumatology, 33, 668-673. http://dx.doi.org/10.1093/rheumatology/33.7.668

[2] Startoris, D.J. (1994) Coding and Reimbursement Issues for Dual-Energy X-Ray Absorptiometry. American Journal of Roentgenology, 163, 137-139. http://dx.doi.org/10.2214/ajr.163.1.8010200

[3] Prince, R.L., Smith, M., Dick, M.I., Price, R.I., Webb, P.G., Henderson, N.K. and Harris, M.M. (1991) Prevention of Postmenopausal Osteoporosis. A Comparative Study of Exercise, Calcium Supplementation and Harmone-Replacement Therapy. The New England Journal of Medicine, 325, 1189-1195.

http://dx.doi.org/10.1056/NEJM199110243251701

[4] Dawson-Hughes, B., Harris, S.S., Krall, E.A. and Dallal, G.E. (1997) Effect of Calcium and Vitamin D Supplementation on Bone Density in Men and Women 65 years of Age or Older. The New England Journal of Medicine, 337, 670676.

[5] WHO Study Group (1994) Assessment of Fracture Risk and Its Application to Screening for Post Menopausal Osteo- 
porosis. WHO Technical Report Series 843, Geneva.

[6] Packe, G.E., Douglas, J.G., McDonald, A.F., Robins, S.P. and Reid, D.M. (1992) Bone Density in Asthmatic Patients Taking High Dose Inhaled Beclomethasone Dipropionate and Intermittent Systemic Corticosteroids. Thorax, 47, 414417. http://dx.doi.org/10.1136/thx.47.6.414

[7] Toussirot, E., Michel, F. and Wendling, D. (2001) Bone Density, Ultrasound Measurements and Body Composition in Early Ankylosing Spondylitis. Rheumatology, 40, 882-888. http://dx.doi.org/10.1093/rheumatology/40.8.882

[8] Kumar, V., Kalita, J., Gujral, R.B., Sharma, V.P. and Misra, U.K. (2001) A Study of Bone Densitometry in Patients with Complex Regional Pain Syndrome after Stroke. Postgraduate Medicine Journal, 77, 519-522. http://dx.doi.org/10.1136/pmj.77.910.519

[9] Smith, R., Athanasou, N.A., Ostlere, S.J. and Vipond, S.E. (1995) Pregnancy Associated Osteoporosis. QJM, 88, 865878.

[10] Kalkwarf, H.J., Specker, B.L., Bianchi, D.C., Ranz, J. and Ho, M. (1997) The Effect of Calcium Supplementation on Bone Density during Lactation and after Weaning. The New England Journal of Medicine, 337, 523-528. http://dx.doi.org/10.1056/NEJM199708213370803

[11] Borders, J., Kerr, E., Sartoris, D.J., Stein, J.A., Ramos, E., Moscona, A.A. and Rensic, D. (1989) Quantitative Dual Energy Radiographic Absorptiometry of the Lumbar Spine in Vivo Comparison with Dual-Photon Absroptiometry. Radiology, 170, 129-131. http://dx.doi.org/10.1148/radiology.170.1.2909085

[12] Wahner, H.W., Dunn, W.L., Mazees, R.B., Towsley, M., Lindsay, R., Markhard, L. and Dempster, D. (1985) Dual Photon Gd-153 Absorptiometry of Bone. Radiology, 156, 203-206. http://dx.doi.org/10.1148/radiology.156.1.4001406

[13] Arici, M., Erturk, H., Altun, B., Usalan, C., Ulusoy, S., Erdem, Y., Sivri, A., Yasavul, U., Turgan, C. and Caglar, S. (2000) Bone Mineral Density in Haemodialysis Patients: A Comparative Study of Dual-Energy X-Ray Absorptiometry and Quantitive Ultrasound. Nephrology Dialysis Transplantation, 15, 1847-1851. http://dx.doi.org/10.1093/ndt/15.11.1847

[14] Ruegsegger, P., Elsasser, U., Anliker, M., Gnehm, H., Kind, H. and Prader, A. (1976) Qualification of Bone Mineralization Using Computed Tomography. Radiology, 121, 93-97. http://dx.doi.org/10.1148/121.1.93

[15] Yamada, M., Ito, M., Hayashi, K., Ohki, M. and Nakamura, T. (1994) Dual Energy X-Ray Absorptiometry of the Calcaneus: Comparison with Other Techniques to Assess Bone Density and Value in Predicting Risk of Spine Fracture. American Journal of Roentgenology, 163, 1435-1440. http://dx.doi.org/10.2214/ajr.163.6.7992742

[16] Mazess, R.B., Barden, H.S., Bisek, J.P. and Lunar, J.H. (1990) Dual-Energy X-Ray Absorptiometry for Total Body and Regional Bone Mineral and Soft Tissue Composition. American Journal of Clinical Nutrition, 51, 1106-1112.

[17] Ryan, P.J., Blake, G.M., Herd, R., Parker, J. and Fogelman, I. (1994) Post Menopausal Vertebral Osteoporosis: Can Dual Energy X-Ray Absorptiometry Forearm Bone Density Substitute for Axial Measurements? Rheumatology, 33, 546-549. http://dx.doi.org/10.1093/rheumatology/33.6.546

[18] Nagia, S., Arya, V., Verma, B.R., Gujral, R.B. and Mithal, A. (1997) Spinal Bone Mineral Density in Normal Indian Females. ESICON, Lucknow.

[19] Petlay, G.N., Cotton, A.M., Murills, A.J., Taylor, P.A., Cooper, C., Cawley, M.I.D. and Wilkin, T.J. (1996) Reference Ranges of Bone Mineral Density for Women in Southern England: The Impact of Local Data on the Diagnosis of Osteoporosis. The British Journal of Radiology, 69, 655-660. http://dx.doi.org/10.1259/0007-1285-69-823-655

[20] Anburajan, M., Rethinasabapathy, C., Korath, M.P., Ponnappa, B.G., Kumar, K.S., Panicker, T.M.R., Govindan, A., Prasad, G.N.S. and Jagadeesan, K. (2001) Age Related Proximal Femur Bone Mineral Loss in South Indian Women: A Dual Energy X-Ray Absorptiometry Study. Journal of the Association of Physicians of India, 49, 442-445. 